\title{
Pengembangan Jalamba sebagai Ornamen Arsitektural pada Rumah
}

\author{
${ }^{1}$ Abdi Gunawan Djafar, ${ }^{2}$ Ernawati \\ 1,2 Program Studi Arsitektur, Fakultas Teknik, Universitas Negeri Gorontalo \\ e-mail: abdi djafar@ung.ac.id
}

\begin{abstract}
Abstrak
Jalamba adalah pagar adat khas daerah Gorontalo yang keberadaannya menunjukkan kepada orang-orang yang melihatnya bahwa ada hajatan yang akan, sedang, dan telah digelar di tempat tersebut. Selain pada kegiatan adat, jalamba juga dapat ditemukan pada teras rumah panggung serta pada beberapa bangunan seperti masjid. Penggunaan jalamba pada rumah panggung dan masjid menunjukkan bahwa jalamba tidak terikat pada kegiatan adat dan dapat digunakan sebagai elemen arsitektural yang bisa menunjukkan kekayaan budaya Gorontalo. Penelitian ini akan membahas mengenai pengembangan jalamba dengan fokus pada jenis bangunan hunian atau rumah sebagai langkah awal yang dapat menjadi percontohan untuk dikembangkan pada jenis bangunan-bangunan lainnya. Penelitian ini merupakan penelitian kualitatif. Data didapatkan melalui kajian literatur, dan pengamatan di lapangan. Literatur yang dikaji berupa buku, artikel internet, dan jurnal penelitian. Hasil penelitian menunjukkan pengembangan jalamba sebagai elemen arsitektural pada rumah ini didasarkan atas usaha untuk mengembangkan bagian dari budaya Gorontalo untuk dilestarikan menjadi bagian dari rumah modern arsitektur kontemporer.
\end{abstract}

Kata kunci: Jalamba; Pengembangan; Dekorasi rumah

\begin{abstract}
Jalamba is a traditional fence from Gorontalo whose existence shows to people who sees it that there will be a celebration, going on, and has been held in that place. Apart from the customary activities, jalamba also can be found in front of the house on stilts and on the other place like the mosque. The use of jalamba of the house on stilts and the mosque shows that jalamba is not attached to the customary activities and can be used as the architectural elements that can show the cultural richness of Gorontalo. This research will discuss the development of the jambala with a focus on residential building types or a house in the first step that could be piloted to develop in other types of other buildings. This research is qualitative, data obtained trough studies, literature, and field observations. The literature being reviewed is in the form of books, internet articles, and research journals. Research result shows that the development of jalamba as the architectural elements to the house is based on the effort for developing part of the Gorontalo culture to be preserved and become part of the modern house contemporary architecture.
\end{abstract}

Keywords: Jalamba; Development; Home decor

\section{Pendahuluan}

Jalamba adalah pagar adat khas daerah Gorontalo yang saat ini banyak dijumpai pada berbagai kegiatan yang didalamnya terdapat upacara adat seperti pernikahan dan kedukaan (Daulima, 2008). Jalamba diletakkan sebagai pembatas tepian pada teras depan bangunan, keberadaan jalamba menunjukkan kepada orangorang yang melihatnya bahwa ada hajatan yang akan, sedang, dan telah digelar di tempat tersebut. Ini disebabkan jalamba perlu dipasang sebelum kegiatan, dan setelah 
kegiatan selesaipun biasanya jalamba tidak langsung dibongkar oleh pengguna bangunan.

Selain pada kegiatan adat, jalamba juga dapat ditemukan pada teras rumah panggung serta pada beberapa bangunan seperti masjid. Selain berfungsi untuk membatasi ruang dan menjadi pengaman untuk mencegah jatuh dari teras yang tinggi, penggunaan jalamba pada rumah panggung merupakan hasil akulturasi budaya Gorontalo dengan budaya asing yang datang pada abad ke 19 (Adiatmono, 2017). Penggunaan jalamba pada rumah panggung dan masjid menunjukkan bahwa jalamba tidak terikat pada kegiatan adat dan dapat digunakan sebagai elemen arsitektural yang bisa menunjukkan kekayaan budaya Gorontalo.

Jalamba terdapat dalam bentuk permanen dan temporer. Untuk kegiatan adat, digunakan jalamba yang konstruksinya mudah dipasang dan dilepas (temporer) dengan sambungan-sambungan sederhana menggunakan bahan seperti bambu kuning yang merupakan tanaman adat Gorontalo, seperti terlihat pada gambar 1. Sedangkan jalamba permanen adalah jalamba yang digunakan pada rumah panggung, berfungsi untuk menjaga pengguna agar tidak jatuh dari ketinggian sehingga pagar ini tidak perlu untuk dilepaskan dan konstruksinya perlu menggunakan material yang tahan lama dan sambungan yang kaku, seperti terlihat pada gambar 2. Rumah moderen saat ini memiliki elevasi yang tidak terlalu tinggi dari permukaan tanah sehingga pagar pengaman tidak diperlukan keberadaannya. Ketika upacara adat akan diselenggarakan pada rumah moderen ini, maka jalamba yang sifatnya temporer dipasang, dan ketika selesai kondisi rumah kembali ke awal sebagai rumah tanpa pagar pada terasnya.

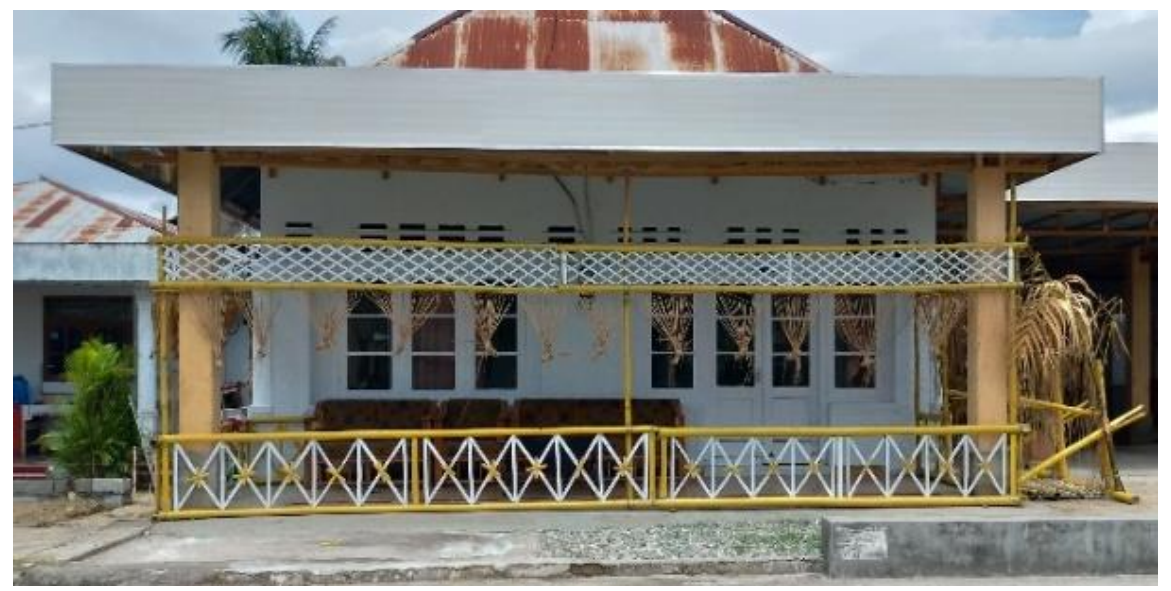

Gambar 1 Jalamba yang Digunakan dalam Kegiatan Adat di Sebuah Rumah 


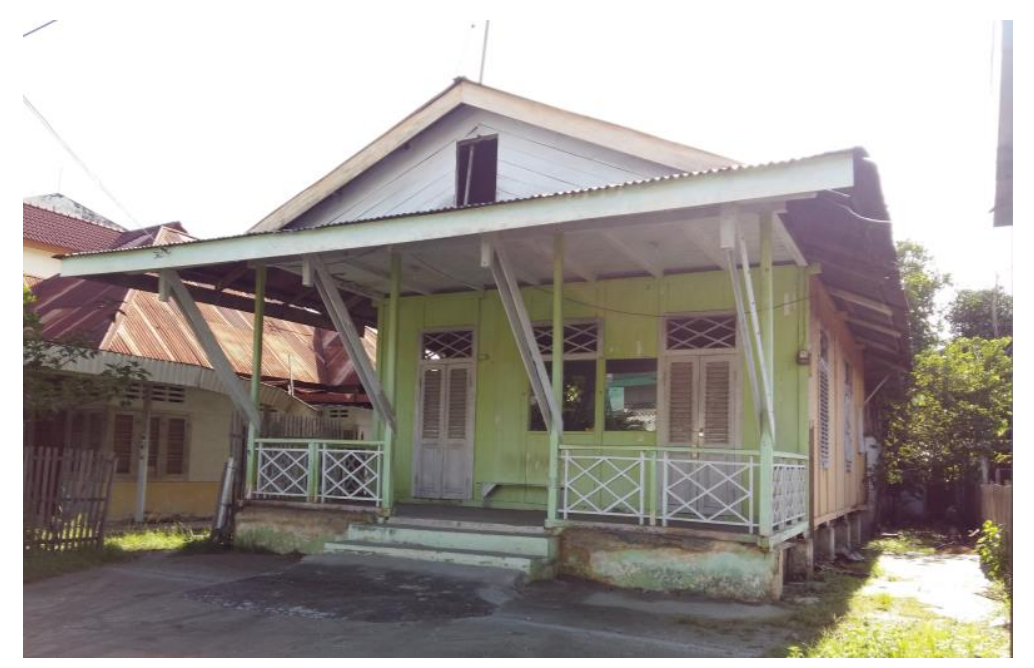

Gambar 2 Jalamba yang Digunakan pada Sebuah Rumah Berpanggung

Pagar pinggiran teras pada rumah panggung juga ditemukan pada berbagai bangunan tradisional lainnya di Indonesia. Diantaranya Tondok in Gandaria pada rumah panggung di Bolaang Mongondow, pagar Tenggalung pada rumah di Palembang, pagar Kandang Rasi pada rumah panggung di Kalimantan Selatan, dan lain-lain. Pagar-pagar ini memiliki bentuk dan pola hiasnya yang unik antara satu dan lainnya.

Sebagai bangunan yang bernilai tradisi dan sejarah, pagar pada rumah panggung ini perlu dilestarikan. Namun kenyataannya, banyak pagar pada rumah panggung yang mengalami perubahan yaitu pada material seperti pagar pembatas teras yang disebut lego-lego pada rumah panggung di Sulawesi Selatan diubah menggunakan material besi (Beddu et al., 2018), dan pagar pembatas yang disebut Langkan pada rumah tradisional Betawi, yang diberi tambahan besi dengan bentukbentuk ragam geometris (Wijayanti et al., 2019).

Perubahan seperti dicontohkan di atas merupakan upaya menyesuaikan warisan arsitektur dengan kondisi saat ini dimana trend arsitekturnya menggunakan teknologi moderen yang memberikan nilai lebih dalam estetika, kemudahan konstruksi dan ketahanannya dalam pembangunan rumah dan pembuatan ornamennya. Mengembangkan atau menjadikan moderen adalah cara terbaik untuk menjadi tradisional, karena memoderenkan tradisi adalah cara terbaik untuk melestarikannya (Savio, 2006).

Dijelaskan oleh Daulima dalam bukunya, jalamba memiliki beragam pola dan penggunaan yang membuatnya unik dibandingkan dengan pagar pada rumah panggung lainnya. Namun sayangnya sebagian besar polanya sudah tidak dapat ditemukan saat ini. Perlu ada upaya untuk menghidupkan kembali jalamba dengan 
pola-polanya untuk melestarikan budaya Gorontalo melalui langkah seperti pengembangan. Dalam upaya pengembangan ini akan diberi penekanan dalam menjaga nilai-nilai yang terkandung di dalamnya agar tidak sekedar menjadi elemen dekorasi tanpa konsep yang kuat. Jalamba yang dikembangkan agar tidak hanya digunakan pada rumah, namun juga bangunan perkantoran pemerintah dengan cara mengkreasikan pola jalamba menjadi desain menarik sebagai elemen fasad, interior, plafon.

Penelitian ini membahas mengenai pengembangan jalamba dengan fokus pada jenis bangunan hunian atau rumah sebagai langkah awal yang dapat menjadi percontohan untuk dikembangkan pada jenis bangunan-bangunan lainnya.

\section{Metode}

Penelitian ini merupakan penelitian kualitatif. Data didapatkan melalui kajian literatur, dan pengamatan di lapangan. Literatur yang dikaji berupa buku, artikel internet, dan jurnal penelitian. Kajian literatur ditujukan untuk memahami jenis dan ragam jalamba serta pengguna dan penggunaannya. Pengamatan di lapangan dilakukan untuk melihat jenis jalamba yang digunakan pada rumah serta bangunanbangunan lainnya yang mungkin menggunakan jalamba sebagai ornamennya. Data ini digunakan untuk membuat konsep dasar berupa nilai-nilai dari jalamba yang menjadi acuan dalam mengembangkannya menjadi elemen dekorasi pada berbagai bagian dari rumah.

Proses pengembangan dilakukan dengan mengikuti prinsip yaitu penerapan nilai-nilai jalamba pada elemen dekorasi bangunan yang sesuai, yang bisa menjaga nilai jalamba yang aslinya sehingga masih dapat dipahami oleh penggunanya dan orang yang melihatnya. Berikutnya adalah membuat desain dan visualisasi 3 dimensi dari pengembangan jalamba untuk memberikan gambaran jelas tentang penerapan jalamba yang telah dikembangkan ke dalam bangunan.

Proses pengembangan jalamba dilakukan melalui 3 tahapan. Tahapan pertama adalah mempelajari jenis dan makna jalamba yang diperoleh dari tahapan pengumpulan data. Tahapan kedua adalah mempelajari nilai-nilai dari jalamba berdasarkan pengguna dan penggunaannya, dimana dapat disarikan sifat-sifatnya seperti privat dan publik, temporer dan permanen, dan nilai-nilainya seperti rendah dan tinggi, sekunder dan primer/utama, dan nilai-nilai khusus sesuai penggunaan spesifik dari jalamba tersebut. Tahapan ketiga adalah menerapkan desain jalamba dengan pada elemen dekorasi bangunan yang sesuai dengan nilai jalamba tersebut. Dari berbagai elemen bangunan seperti fasad, teras, dinding, pintu, plafon, dan lain-lainnya, 
dipilih elemen yang paling sesuai fungsinya dengan nilai dari jalamba. Elemen terpilih menjadi media untuk diterapkan pola jalamba.

\section{Hasil dan Pembahasan}

Hasil

Berdasarkan penjelasan Daulima (2008), terdapat 6 jenis jalamba, seperti tersaji pada tabel 1.

Tabel 1 Klasifikasi Jalamba

\begin{tabular}{clll}
\hline No & \multicolumn{1}{c}{ Jenis } & \multicolumn{1}{c}{ Pengguna } & \multicolumn{1}{c}{ Penggunaan } \\
\hline 1 & Mohimato lo unggu & Masyarakat biasa & Digunakan ketika hajatan \\
2 & Pobiya & Semua golongan & Digunakan ketika pesta rakyat \\
3 & Ungala'a & Pejabat kerajaan & Digunakan ketika hajatan \\
4 & Pakadanga & Pemimpin daerah & Digunakan pada rumah \\
5 & Wolihi & Raja & Digunakan pada rumah \\
6 & Layahu & Semua golongan & $\begin{array}{l}\text { Digunakan ketika ada hajatan yang } \\
\text { bercampur dengan adat dari daerah }\end{array}$ \\
& & lain \\
\hline
\end{tabular}

Tampilan keenam jalamba tersebut memiliki tampilan seperti digambarkan pada gambar 3.

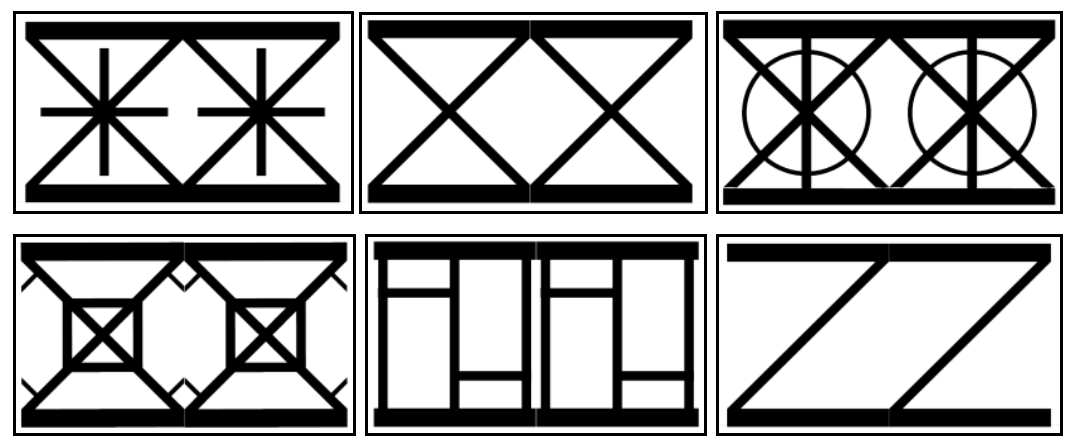

Gambar 3 (Atas dari kiri ke kanan) Jalamba Mohimato lo Unggu, Pobiya, Ungala'a.

(Bawah dari kiri ke kanan) Jalamba Pakadanga, Wolihi, dan Layahu

Jalamba ungala'a dan layahu digambar berdasarkan interpretasi penulis terhadap deskripsi jalamba oleh Daulima. Sedangkan 4 jalamba lainnya tergambarkan pada literatur tersebut. Jalamba digunakan oleh penggunanya sesuai dengan pembagian golongan/ strata sosial dalam masyarakat Gorontalo zaman dulu. Dimana terdapat 4 golongan yaitu masyarakat biasa, pejabat kerajaan, pemimpin daerah, serta raja.

Menurut maknanya, ungala'a adalah kekerabatan, pakadanga adalah hiasan untuk bagian tengah (badan) rumah seperti bentuk ventilasi di atas jendela, dan lisplang/papan pinggir pada atap, wolihi berarti tiang, dan layahu berarti layer. Maknamakna ini dapat menjadi satu konsep yang dapat digunakan untuk mengembangkan jalamba pada bangunan-bangunan moderen. 
Jalamba pakadanga dan wolihi merupakan jalamba yang digunakan pada rumah pemimpin-pemimpin zaman kerajaan Gorontalo sehingga dapat dikembangkan secara langsung untuk diterapkan pada bangunan misalnya rumah moderen. Namun jalambajalamba lainnya tidak memiliki penjelasan tentang penggunaannya pada rumah, untuk itu perlu mempelajari nilai-nilai dari jalamba yang ada agar dapat dicarikan kesesuaiannya untuk dikembangkan sebagai elemen dekorasi pada rumah.

Berdasarkan jenis dan makna jalamba pada tabel 1 dan gambar 3 , dibuat tabel perbandingan nilai-nilai yang telah disarikan dari makna jalamba seperti ditunjukkan pada tabel 2.

Tabel 2 Penyarian Nilai Jalamba

\begin{tabular}{|c|c|c|c|}
\hline No & Nama jalamba & Konteks & Nilai \\
\hline 1 & Mohimato lo unggu & $\begin{array}{l}\text { Masyarakat biasa } \\
\text { Diqunakan ketika haiatan }\end{array}$ & $\begin{array}{l}\text { Rendah } \\
\text { Khalavak ramai }\end{array}$ \\
\hline 2 & Pobiya & $\begin{array}{l}\text { Semua golongan } \\
\text { Digunakan ketika pesta rakyat }\end{array}$ & $\begin{array}{l}\text { Umum } \\
\text { Festival, menarik perhatian }\end{array}$ \\
\hline 3 & Ungala'a & $\begin{array}{l}\text { Pejabat kerajaan } \\
\text { Digunakan ketika hajatan }\end{array}$ & $\begin{array}{l}\text { Menjaga kesejahteraan } \\
\text { masyarakat dan } \\
\text { keberlangsungan } \\
\text { pemerintahan. } \\
\text { Khalayak ramai }\end{array}$ \\
\hline 4 & Pakadanga & $\begin{array}{l}\text { Pemimpin daerah } \\
\text { Digunakan pada rumah }\end{array}$ & $\begin{array}{l}\text { Sekunder, Besar, Tinggi } \\
\text { Privat }\end{array}$ \\
\hline 5 & Wolihi & $\begin{array}{l}\text { Raja } \\
\text { Digunakan pada rumah }\end{array}$ & $\begin{array}{l}\text { Primer, Besar, Tinggi } \\
\text { Privat }\end{array}$ \\
\hline 6 & Layahu & $\begin{array}{l}\text { Digunakan ketika ada hajatan } \\
\text { yang bercampur dengan adat dari } \\
\text { daerah lain }\end{array}$ & $\begin{array}{l}\text { Percampuran adat } \\
\text { Khalayak ramai }\end{array}$ \\
\hline
\end{tabular}

Terdapat banyak interpretasi yang dapat timbul untuk menerapkan nilai-nilai dari jalamba pada bangunan, namun untuk mengerucutkan pembahasan maka jenis bangunan yang akan difokuskan pada penelitian ini adalah rumah tinggal. Jalamba pobiya memiliki nilai yaitu umum dimana jalamba ini dapat digunakan oleh siapapun serta memiliki nilai sebagai penarik perhatian atau focal point sehingga jalamba dapat diterapkan sebagai elemen dekorasi misalnya pada fasad (bagian depan rumah).

Untuk merangkum dan menjelaskan kembali jalamba-jalamba yang mengalami proses pengembangan serta konsep pengembangannya sebagai elemen dekorasi dapat dilihat penjelasan pada tabel 3.

Tabel 3 Pengembangan Jalamba pada Bangunan Berjenis Rumah

\begin{tabular}{clll}
\hline No & Jenis Jalamba & Nilai & Konsep pengembangan \\
\hline 1 & Pobiya & $\begin{array}{l}\text { Penarik } \\
\text { perhatian }\end{array}$ & $\begin{array}{l}\text { Sebagai elemen dekorasi pada fasad (bagian } \\
\text { depan rumah) }\end{array}$ \\
2 & Pakadanga & Hiasan & $\begin{array}{l}\text { Sebagai hiasan partisi, atau sekat antara ruangan, } \\
\text { sebagai hiasan dinding }\end{array}$ \\
3 & Wolihi & Tinggi & $\begin{array}{l}\text { Sebagai elemen dekorasi pada plafon atau menjadi } \\
\text { hiasan ventilasi yang posisinya di bawah plafon } \\
\text { (lebih tinggi dari jalamba lainnya) }\end{array}$ \\
\hline
\end{tabular}


Setelah mendapatkan konsep pengembangan, berikutnya adalah menerapkannya pada desain rumah moderen seperti disajikan pada gambar 4, gambar 5, dan gambar 6 .
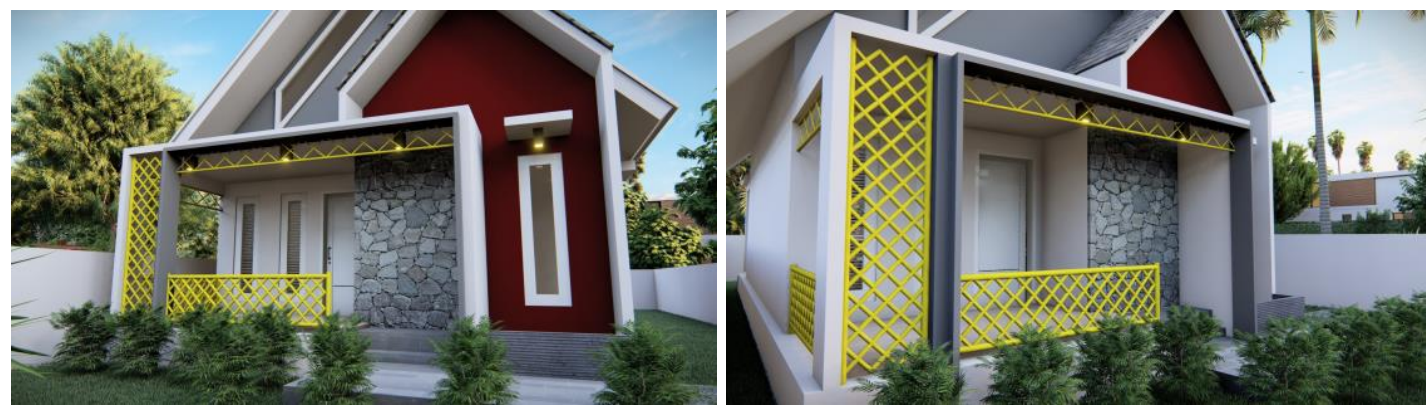

Gambar 4 Pengembangan Jalamba Pobiya sebagai Elemen Fasad
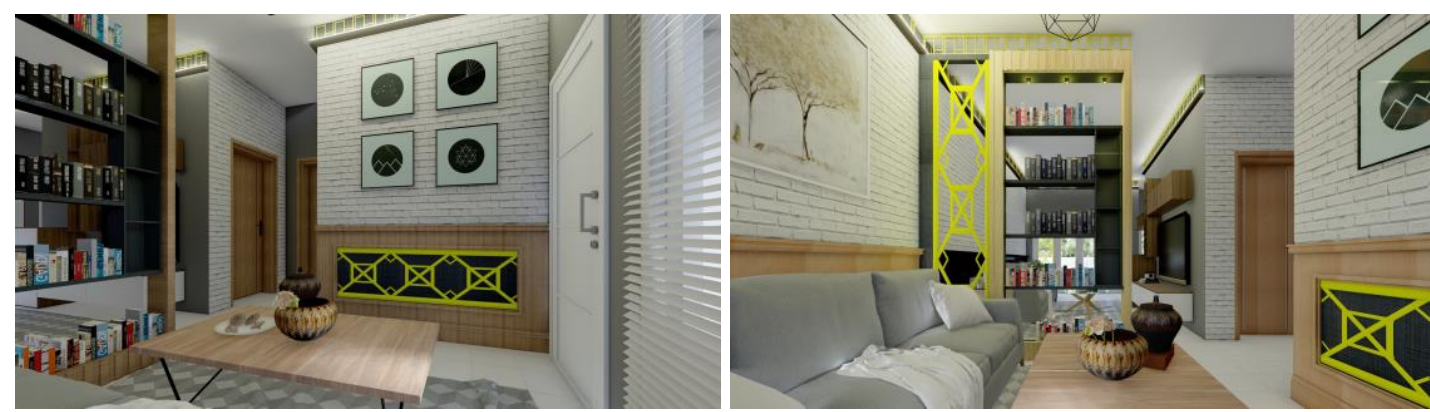

Gambar 5 Pengembangan Jalamba Pakadanga sebagai Elemen Partisi dan Penghias Dinding
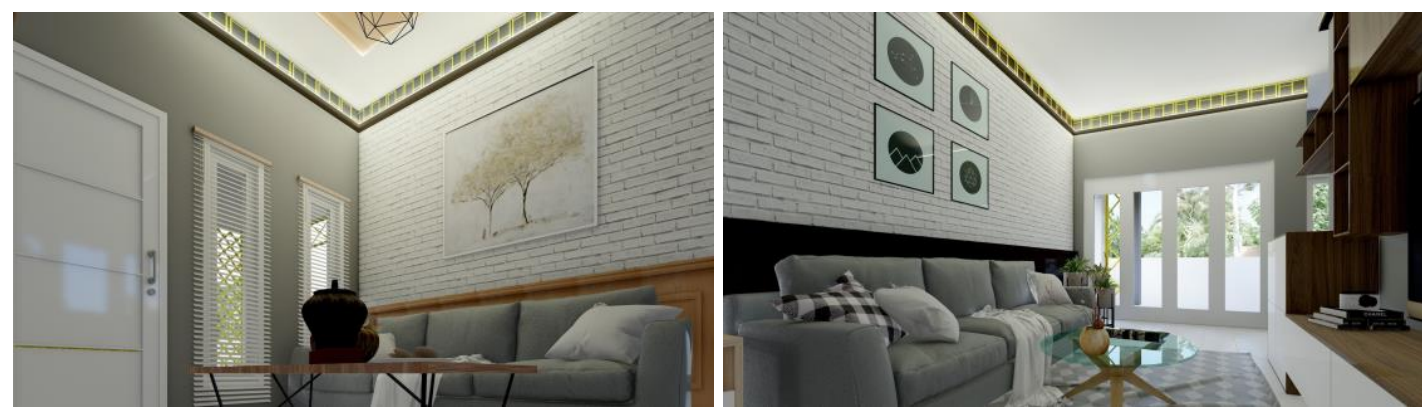

Gambar 6 Pengembangan Jalamba Wolihi sebagai Elemen Plafon

\section{Pembahasan}

Pengembangan jalamba sebagai elemen dekorasi arsitektur ini merupakan sebuah bentuk transformasi secara tradisional (Antoniades, 1992) yaitu sebuah metode transformasi yang melakukan penyesuaian bentuk dengan batasan-batasan internal dan eksternal. Batasan internal yang dimaksud adalah nilai-nilai atau makna dari jalamba, dan batasan eksternal yang dimaksud adalah bentuk fisik dari jalamba itu sendiri. Metode ini dipilih sebagai cara yang paling sederhana dalam melakukan pengembangan yang menjaga keaslian nilai-nilainya, terlebih lagi dengan memperhatikan jalamba sebagai suatu warisan budaya yang harus dilestarikan.

Pada penelitian yang serupa, terdapat penerapan batik sebagai elemen bentuk dan 
massa bangunan dengan metode transformasi dan analogi dari corak batik untuk menghasilkan bentuk baru (Fatma et al., 2013). Tujuan penelitian tersebut adalah menciptakan bangunan dengan visual batik pada sebuah kawasan kampung batik. Dengan demikian, citra area kampung yang menghasilkan batik semakin ditegaskan.

Proses pengembangan jalamba yang dilakukan melalui penyarian makna dan nilai jalamba pada penelitian ini merupakan bentuk elaborasi dari proses yang juga digunakan oleh Heryati dan Nurnaningsih (2015) yang menggunakan variabel semantik arsitektur dalam melakukan transformasi arsitektur vernakular Gorontalo pada bangunan masa kini, yang didasarkan atas subteori Hjelmslev dalam Umberto Eco (dalam Broadbent et al., 1980). Teori ini membagi sesuatu menjadi 2 entitas yaitu content dan expression seperti terlihat pada tabel 4 .

Tabel 4 Contoh pengembangan jalamba dengan teori semantik

\begin{tabular}{|c|c|c|c|}
\hline Content Form & Content Substance & Expression Form & Expression Substance \\
\hline Jalamba pobiya & $\begin{array}{l}\text { Festival, menarik } \\
\text { perhatian }\end{array}$ & $\begin{array}{l}\text { Elemen yang dapat } \\
\text { digunakan oleh semua } \\
\text { kalangan, bebas } \\
\text { Elemen arsitektural } \\
\text { yang dapat langsung } \\
\text { terlihat, tidak tertutupi, } \\
\text { menarik, } \\
\text { mengesankan }\end{array}$ & $\begin{array}{l}\text { Diwujudkan sebagai } \\
\text { sebuah elemen dekorasi } \\
\text { yang terletak di selubung } \\
\text { bangunan seperti dinding } \\
\text { atau atap yang dapat } \\
\text { terlihat dari luar dan } \\
\text { menarik perhatian bagi } \\
\text { yang melihatnya }\end{array}$ \\
\hline
\end{tabular}

Meskipun metode yang digunakan dalam penelitian ini memiliki tahapan yang lebih panjang dibanding metode yang menggunakan teori semantik, namun pentahapan tersebut dinilai lebih dapat menjelaskan proses pengembangan, terlebih karena penelitian ini memfokuskan pada bangunan rumah dimana tidak semua jalamba yang ada dapat dikembangkan sebagai elemen dekorasi pada jenis bangunan hunian sehingga prosesnya selektif terhadap beberapa jenis saja.

\section{Kesimpulan}

Penelitian tentang pengembangan jalamba sebagai elemen arsitektural pada rumah ini didasarkan atas usaha untuk mengembangkan bagian dari budaya Gorontalo untuk dilestarikan menjadi bagian dari rumah moderen. Jalamba yang permanen tidak hanya dapat ditemukan pada rumah panggung warisan namun juga dapat ditemukan pada bangunan rumah moderen. Proses pengembangan yang dilakukan dengan syarat tanpa mengubah nilai aslinya ternyata menghadapi masalah bahwa tidak semua jenis jalamba sesuai untuk digunakan pada jenis bangunan rumah karena adanya ketidakcocokan nilai antara jalamba sebagai sumber dan rumah sebagai targetnya. 
Penelitian tentang pengembangan atau transformasi arsitektur Gorontalo ke dalam arsitektur moderen ini dapat menjadi penambah khazanah tentang penelitian-penelitian serupa yang bertujuan untuk melestarikan budaya Gorontalo. Penelitian ini diharapkan dapat menjadi acuan dalam perancangan bangunan di Gorontalo yang akan menerapkan unsur-unsur budaya Gorontalo ke dalam rancangannya

\section{Daftar Pustaka}

Adiatmono, F., (2017). The Ornament of Gorontalo Traditional Houses: Aesthetic And Symbolic Study. Conference on Education and Cultural Heritage, Brussels, 1, 94-111.

Antoniades, A. C. (1992). Poetics of Architecture. New York: Van Nostrand Reinhold.

Beddu, S., Martosenjoyo, T., Latief, M.S., Ishak, R.A., (2018). Perubahan Bentuk Fasade Arsitektur Rumah Panggung Bugis di Sulawesi Selatan (Studi tentang Perubahan Bentuk Lego-Lego atau Teras). Prosiding Seminar IImiah Nasional Sains dan Teknologi, 4, 25-34.

Broadbent, Geoffrey, Bunt, R., \& Jencks, C. (1980). Sign, Symbol \& Architecture. New York: John Willey and Sons.

Daulima, F. (2008). Dialog tentang Budaya Daerah bersama Bunda Farha D. Gorontalo: Galeri Budaya Daerah LSM Mbu'i Bungale.

Mutia, F., Pamungkas, S.T., \& Ridjal, A.M. (2013). Penerapan Citra Visual Batik pada Elemen Perancangan Bentuk dan Massa Bangunan Kampung Batik Jetis Sidoarjo. Jurnal Mahasiswa Jurusan Arsitektur Brawijaya, 1(1), 1-13,

Heryati, \& Nurnaningsih, N.A. (2015). Transformasi Arsitektur Vernakular Gorontalo Pada Bangunan Masa Kini Untuk Memperkuat Identitas Daerah Studi Aplikasi pada Bangunan Kantor Pemerintahan. Jurnal Teknik, 13(1), 40-58.

Savio, A. (2006). The Spirit of The New. Roskilde University: Denmark.

Wijayanti, G., Chintya, R., \& Nurhasanah. (2018). Penerapan Balaksuji dan Langkan pada Rumah Tradisional Betawi di Kampung Betawi, Jakarta Selatan. Jurnal UNTAR Mezanin, 1(1), 47-59. 